\section{Vol. 68, No. 36}

In the report "Severe Pulmonary Disease Associated with Electronic-Cigarette-Product Use - Interim Guidance" an author's affiliation should have read as follows:

Dana Meaney-Delman, MD ${ }^{12}{ }^{12}$ Division of Birth Defects and Infant Disorders, National Center on Birth Defects and Developmental Disabilities, CDC.

In addition, the following person should have been included among the members of the CDC 2019 Lung Injury Response Group:

Livia Navon (Center for Preparedness and Response, Division of State and Local Readiness, assigned to the Illinois Department of Health).

\section{Vol. 68 , No. 36}

In the report "Notes from the Field: Interventions to Reduce Measles Virus Exposures in Outpatient Health Care Facilities - New York City, 2018," on page 791, the Acknowledgments should have read "L. Hannah Gould, New York City Department of Health and Mental Hygiene; Mona Marin, Jennifer Wright, Zeshan Chisty, CDC; all staff members from participating health care facilities in New York City." 